\title{
Ciência Econômica e Trabalho
}

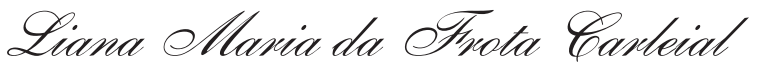

Professora Visitante do Setor de Ciências Jurídicas da Universidade Federal do Paraná, Economista, Doutora em Teoria Econômica pela USP e Bolsista do CNPq.

\section{Introdução ${ }^{1}$}

\section{SUMÁRIO}

Introdução;

1 A economia política clássica: o trabatho humano e a origem da riqueza capitalis$t a$;

2 A crise da economia política clássica e sua superação;

3 Trabalho e teoria marxista;

40 trabalho es grandes agregados econômicos;

Considerações finais: Em que os auxilia a teoria econômica?

Referências bibliográficas.

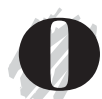

objetivo deste artigo é apresentar, de modo preliminar, os caminhos que a ciência econômica seguiu no que se refere à compreensão da natureza do trabalho. A economia se individualiza, enquanto ciência, na fase de desenvolvimento mais intenso da manufatura e coincide, historicamente, com a consolidação do capitalismo como modo de produção. Logo, a natureza aqui referida é a do trabalho capitalista.

A razão para este artigo é a dificuldade real enfrentada hoje no trato analítico da categoria trabalho, dificuldade essa que, a meu ver, é generalizada para as ciências sociais e humanas. Para alguns autores, como por exemplo, HABERMAS (1987), GORZ (1988), OFFE (1986) tais problemas refletem a perda de centralidade desta categoria à medida que o capitalismo se torna mais complexo.

1 Versão modificada deste artigo foi apresentada no XX Encontro Anual da Anpec - Associação Nacional dos Centros de Pós-graduação em Economia, em Campos do Jordão, em dezembro de 1992. 
A meu juízo essa perda de centralidade é aparente e as dificuldades derivam da complexidade que também atinge as formas de trabalho que coexistem neste estágio do desenvolvimento histórico, as quais não têm merecido reflexão adequada que permita a sua incorporação pelas distintas elaborações teóricas.

Tem-se claro que esta é uma tarefa coletiva e interdisciplinar, porém é interessante refletir esta questão do ângulo da contribuição da economia. Espera-se, então, responder: em que medida a construção da teoria econômica nos ajuda a entender a natureza do trabalho.

Este artigo está estruturado em quatro partes além desta introdução e das considerações finais. $\mathrm{Na}$ primeira, situa-se o rompimento da economia política clássica com o mercantilismo, a partir da afirmação da origem da riqueza capitalista. Como se sabe, para os mercantilistas, a riqueza era proveniente do acúmulo de metais preciosos, cuja origem se dava pelas trocas desiguais de valor na circulação e, portanto, decorrentes de diferenças entre os preços de compra e os preços de venda. A colocação do trabalho no centro da discussão vai se estabelecer a partir da elaboração Clássica (SMITH e RICARDO). Na segunda parte, trata-se da chamada crise da economia política clássica e da ruptura teórica que se segue, abrindo espaço para as contribuições da teoria do valor-trabalho marxista e da teoria do valor-utilidade. $\mathrm{Na}$ terceira parte, afirma-se a contribuição de MARX para o entendimento do trabalho sob o capital. Na quarta parte, incorpora-se o marco da revolução keynesiana quando a preocupação com o trabalho é substituída pelo emprego. Finalmente, na última seção faz-se alguns comentários, procurando contribuir para a resposta à questão central proposta.

São muitas as dificuldades metodológicas neste tipo de estudo. Em primeiro lugar, é difícil buscar o entendimento do estatuto do trabalho em algumas contribuições teóricas per se. Ou seja, muitas vezes este entendimento está condicionado ao entendimento da obra como um todo, bem como à questão central colocada por cada autor. Por tal razão, em alguns casos tornase necessário expor um pouco tal entendimento. Em segundo lugar, vai ficar evidente que, em alguns momentos, a análise estará tratando de trabalho, noutros de trabalhadores e noutros ainda dos efeitos das variações dos agregados econômicos sobre os trabalhadores. Este tipo de desdobramento pode aparentemente ser entendido como um afastamento do objeto central, qual seja, o trabalho. No entanto, parece ser mais realista entender este procedimento como uma conseqüência do próprio desenvolvimento da Ciência Econômica na qual o trabalho perde mesmo a sua relevância. Em terceiro lugar, é importante esclarecer que entre os autores referidos há diferenças metodológicas, de visão de mundo e até mesmo do entendimento do que seja ciência. No entanto, no âmbito deste artigo estas diferenças não serão contempladas.

Finalmente, destaca-se mais uma vez o caráter preliminar desta incursão a qual deverá fornecer as bases para a elaboração de um roteiro de pesquisa teórica a ser desenvolvida futuramente. 


\section{A economia política clássica: o trabalho humano e a origem da riqueza capitalista}

A demarcação do que é economia política clássica por si só é uma tarefa complicada. Para fins deste artigo pretende-se considerá-la submetida à avaliação marxista que faz sua demarcação, a partir do desejo dos economistas em desvendar os nexos internos da sociedade burguesa (independente dos resultados obtidos) quando contrapostos àqueles que apenas buscam explicações para os fenômenos dessa sociedade. Ou seja, os economistas clássicos e os economistas vulgares. Desse modo, aqui entende-se ADAM SMITH e RICARDO como os economistas clássicos por excelência. (MARX, 1978, cap. 1, p. 90).

A principal contribuição deste pensamento foi a ruptura com o mercantilismo por apontar o trabalho humano como central para o entendimento da origem e do crescimento da riqueza capitalista. É evidente que a ruptura, do ponto de vista do entendimento da natureza da economia capitalista, já havia sido efetivada pelo pensamento fisiocrático que só considerava possível a geração do excedente na produção e não na circulação. Entretanto, para os fisiocratas a riqueza era oriunda da agricultura, e a terra, então, era a questão central.

SMITH herda da fisiocracia o primado da produção, porém, coloca na origem da riqueza o trabalho, generalizando para todos os setores da economia a possibilidade de geração do excedente. Associandose à LOCKE, SMITH entende o trabalho como a única possibilidade do homem, na sociedade comercial, transformar-se em proprietário e individualizar-se. Assim, o par - trabalho e mercado - define a modernidade para ele.

trabalho para SMITH é entendido como dispêndio de esforço, dispêndio de energia; esforço esse que é trocado no mercado por dinheiro. Desse modo, no primeiro instante em que o trabalho aparece na construção da economia, ele aparece enquanto esforço, cansaço físico. Por isso, ele é o primeiro preço a ser pago (SMITH, 1983, livro 1 cap. v, p. 63). Como o importante para SMITH é responder porque as nações crescem, a preocupação com a origem do valor já surge subordinada às questões de proporções de troca, divisão do trabalho e crescimento da produtividade.

Assim, partindo do suposto de que todo homem é egoísta e, portanto, detentor de uma propensão natural a trocar, fica estabelecida a necessidade da divisão do trabalho. Do ponto de vista da natureza do trabalho, para SMITH, é possível sempre, de preferência na manufatura, organizá-lo melhor a fim de aumentar a produtividade e a produção. Isto é tão verdadeiro que SMITH enuncia as vantagens da divisão do trabalho como decorrentes do aumento da destreza de cada trabalhador, da economia de tempo que era perdido ao passar de uma operação para outra e finalmente da invenção de um grande número de máquinas que facilitam o trabalho e reduzem o tempo indispensável para a sua realização (SMITH, 1983, livro 1, cap. 1, p. 43-45).

É interessante observar que, já para SMITH, ocorreria no capitalismo, a princí- 
pio, artesãos que produziriam máquinas, mas, posteriormente, a idéia é de que tais máquinas seriam produzidas por um determinado setor de trabalhadores voltados exclusivamente para a criação de novas máquinas.

Para os nossos propósitos é também necessário destacar que, ao discutir os efeitos da divisão do trabalho sobre os trabalhadores, SMITH revela o caráter natural daquela sociedade comercial como ele a entendia. Isto é, no capítulo referente aos Gastos do Soberano (SMITH, 1983, livro V, cap. 1) ele aponta que a divisão do trabalho implica efeitos perversos sobre a população trabalhadora decorrentes da simplificação das tarefas e de sua repetição, reduzindo as possibilidades que os trabalhadores teriam de exercitar sua compreensão para atividades inventivas ou mesmo para superar dificuldades. Mesmo diante de tal entendimento, SMITH conclui que esta era a tendência inexorável daquela sociedade comercial que agora era compreendida como uma sociedade natural e, de acordo com a sua visão histórica, aquela era a sociedade mais desenvolvida e, portanto, seria a forma "eterna".

Do ponto de vista das relações que se estabelecem entre as classes, SMITH é extremamente incisivo ao identificar que o conflito fundamental que se dá no capitalismo é entre capital e trabalho. Ao mesmo tempo, é o primeiro a identificar que ao trabalho corresponde o salário e ao capital, o lucro. Não é novidade também a constatação de que, tanto em RICARDO como em SMITH, há uma certa percepção de uma troca indevida entre trabalho e capi- tal. Ambos percebem que, quando ocorre a apropriação da terra e do capital, o trabalhador deixa de trabalhar apenas para si mesmo e deverá trabalhar também para o patrão. Entretanto, nenhum dos dois consegue estabelecer a diferença entre trabalho e força de trabalho.

Como já referido, para SMITH, o conflito central do capitalismo é o vivido por trabalhadores e capitalistas. Para ele, esse conflito podia ser retratado no confronto entre os que queriam pagar o menos possível e os que queriam receber o máximo possível. Entretanto, para ele, os ganhadores seriam previamente conhecidos. Os capitalistas, por não sofrerem qualquer tipo de restrição aos seus encontros, conluios e reuniões estariam, a cada momento, discutindo a melhor maneira de obter sucesso na sua empreitada. Já os trabalhadores, que sofriam restrições de toda ordem para reunirem-se, o máximo que conseguiriam seria a prisão de seus líderes. A atualidade desta posição smithiana é, entretanto, inteiramente submetida ao filão otimista de sua interpretação do capitalismo.

RICARDO, diferentemente de SMITH, não se dedica à compreensão da natureza do trabalho, apenas concordando com a origem do valor, e da riqueza capitalista, no trabalho. É interessante reter que para RICARDO a questão central da Economia Política seria a distribuição de renda e não o crescimento, como pensara SMITH. Esta questão é abordada primeiramente no artigo Cereais, no qual considera como valor a dificuldade de produzir as mercadorias. Por esta razão, à medida que se torna necessário a incorporação de novas terras 
com qualidades inferiores, aumentando a dificuldade da produção do cereal, aumentam o seu valor e o seu preço. Conseqüentemente, segundo RICARDO, tende a aumentar a participação dos salários na distribuição de renda, impondo redução da participação dos lucros que, a partir daí, passa também a dar conta da parcela referente à renda da terra. Isto, evidentemente, na ausência da importação de cereais e da introdução de progresso técnico. É importante destacar ainda que, para RICARDO, a dificuldade de produção determina o valor das mercadorias e de algum modo esta posição incorpora a idéia de trabalho como esforço (RICARDO, 1985).

No livro Princípios de Economia Politica e Tributação (1817) que se segue ao artigo Cereais (1815), RICARDO estabelece um longo diálogo com SMITH sobre o valor, no qual a questão central é a dificuldade para a mensuração dos valores das mercadorias. Em momento algum, porém, duvida que a origem do valor da mercadoria é o trabalho humano.

A relação ricardiana com o trabalho, enquanto princípio ordenador daquela sociedade, fica mais clara no capítulo referente aos salários à medida que ele assume uma posição crítica em relação à Lei dos Pobres. $\mathrm{Na}$ realidade, RICARDO defende a impropriedade de qualquer ajuda fora do enquadramento necessário ao trabalho. Ou seja, só o trabalho deveria garantir o rendimento. Este entendimento ricardiano pode ser visto como uma defesa da necessária submissão de todos à condição de trabalhadores, bem como o risco para a acumulação se tal não ocorresse (RICARDO, 1983, cap. V, p. 87). Entretanto, para RICARDO, o conflito através do qual ele vê o capitalismo é o conflito entre lucro e renda da terra, uma vez que o salário é dado, no nível de subsistência. A garantia para esta hipótese está no crescimento da população, a uma taxa maior do que o crescimento da demanda por trabalhadores. A influência malthusiana aqui é significativa uma vez que, para MALTHUS, os trabalhadores são os verdadeiros responsáveis por sua miséria.

Observe-se ainda que este aspecto é relevante, pois, vivendo um momento muito mais importante, do ponto de vista da movimentação operária, que SMITH e tendo quase presenciado a liberação do direito de organização dos trabalhadores, que ocorreu na Inglaterra em 1824, RICARDO não consegue perceber os reais efeitos do capital, por exemplo, sobre o emprego. É então no capítulo sobre maquinaria que RICARDO expõe sua posição ambígua so bre este ponto e canaliza a discórdia quanto ao entendimento daquele momento.

Inicialmente, RICARDO afirma que a incorporação do progresso técnico seria benéfica a todas as classes sociais em decorrência da redução dos preços das mercadorias que acarretava. Logo, os trabalhadores também seriam beneficiados, pois os salários poderiam comprar mais. Posteriormente, o autor reconhece que a introdução de máquinas poderia reduzir os recursos destinados à contratação dos trabalhadores e assim toca, mesmo que timidamente, na natureza problemática da criação de empregos sob o capital.

Por outro lado, RICARDO considera inelutável a tendência imanente do 
capitalismo em incorporar progresso técnico, sobretudo quando pensa a concorrência entre os países. Desse modo, a aceitação e incorporação do progresso técnico num determinado país podem impedir que os investimentos migrem para outros países mais progressistas na busca da redução de custos e enfim, na luta pela competitividade.

Mesmo assim, será exatamente a impossibilidade da construção teórica da economia política clássica, de dar respostas ao que está ocorrendo em nível do real-concreto, que fundamenta a crise deste pensamento e a sua posterior superação. De fato, é um certo otimismo com o progresso do capitalismo presente nesta construção que impossibilitará a sua sustentação. Tal otimismo pode ser visualizado através da posição exposta por JACCARD: "o liberalismo econômico da época persuadiu-se de que o enriquecimento de alguns era a condição de felicidade de todos" (JACCARD, 1969, p. 23).

Por outro lado, parece estar assentado exatamente nesta ruptura o rumo que a teoria econômica assumirá no que refere à questão do trabalho.

\section{A crise da economia política clássica e sua superação}

A dificuldade crescente de conceder respostas a uma realidade que teimava em ser diferente da teoria esteve na raiz da crise da economia política clássica. De fato, a complexidade da realidade capitalista é mais manifesta a partir de 1830 e LOWY cita uma passagem muito elucidativa deste aspecto extraída da Miséria da Filosofia, na qual MARX, se referindo aos socialistas e comunistas, afirma:

"Mas à medida que a história avança e com ela a luta do proletariado se delineia mais claramente, ele não tem mais necessidade de procurar a ciência em seu espírito, mas apenas devem se dar conta do que se passa diante dos seus olhos e expressá-lo... A partir desse momento, a ciência produzida pelo movimento histórico, e se associando a ele com plena consciência de causa, deixou de ser doutrinária: ela se tornou revolucionária." (MARX, K. Misére de la Philosofie, p. 100; citado por LOWY, 1990).

A ruptura com a economia política que se faz a partir das dificuldades acima referidas, vai, a meu ver, definir o rumo que o trabalho terá, como categoria analítica no posterior desenvolvimento da ciência econômica. Deste movimento estruturam-se duas novas vertentes que se consideram, num certo sentido, como herdeiras da construção da economia política, as quais expressarão, cada uma a seu modo, "o que se passa diante se seus olhos".

A primeira a ser tratada é a construção que estabelecerá as bases para a elaboração neoclássica. Mesmo diante de algumas diferenças entre si, tais autores (JEVONS - Inglaterra; MENGER - Áustria; WALRÁS - Lausanne) expressam uma absoluta unidade quanto à origem do valor dos bens que estaria na sua utilidade.

Desse conjunto de pensadores relevantes, escolhe-se JEVONS como representativo em razão da explícita proposta de supressão da denominação "economia 
política" e da sua substituição pela denominação "economia" (JEVONS, 1983, Pref. 2. ed., p. 4). É importante destacar este ponto porque, de fato, esta substituição reflete um verdadeiro rompimento com o objeto da economia clássica e, portanto, das questões que eram relevantes. Esta inversão da construção clássica tem implicações inclusive quanto ao próprio objeto da economia, do entendimento do que é ou seria, naquele momento, uma sociedade capitalista e, conseqüentemente, no estatuto do trabalho nas elaborações teóricas posteriores.

Ao negar que a origem do valor das mercadorias produzidas esteja no trabalho humano e afirmá-la na utilidade dos bens, estabelece-se a riqueza como oriunda da terra, do trabalho e do capital e, portanto, fica o trabalho relegado à condição de fator produtivo. Como conseqüência, a estruturação da sociedade em classes sociais que se estabelecem a partir da produção, tradição instalada desde a construção fisiocrática, é substituída por uma estruturação em consumidores e produtores, os quais serão entendidos como firmas, posteriormente. Além disso, a preocupação com o primado da produção, também instituída pela fisiocracia, é substituída pela ótica da circulação.

Tais inversões alteram inteiramente a origem da riqueza capitalista. Para os clássicos (SMITH e RICARDO) a origem da riqueza estava no trabalho; para JEVONS, em decorrência da afirmação do trabalho como fator de produção, ele (o trabalho) perde toda sua proeminência. Este fato, aparentemente sem importância, vai, na realidade, se refletir em todas as elaborações teóricas posteriores.
Entender o trabalho como mero fator de produção dispensa a necessidade de interpretar, como se trabalha, em cada sociedade concreta e em cada momento no tempo. Deste modo, o trabalho seria desprovido de historicidade.

A clivagem entre economia política e economia proposta por JEVONS é responsável também pela possibilidade de se olhar a sociedade através do que acontece com o trabalho dos homens ou, então, olhála pelo movimento dos seus preços, inclusive o do trabalho. Este é um ponto importante porque, como se entende neste artigo, a centralidade nos grandes agregados econômicos vai transformar a contribuição da ciência econômica, para o entendimento do que ocorre com o trabalho, em sucessivas contribuições sobre o comportamento dos salários. Assim, a contribuição da ciência econômica parece ser, fundamentalmente, a contribuição quanto ao comportamento de um preço na economia capitalista.

Contrariamente a outra vertente que se propõe como crítica da economia política clássica, a contribuição marxista, mesmo compromissada em entender o capital, vai centrar sua atenção no estatuto do trabalho sob o capital.

\section{Trabalho e teoria marxista}

Do ponto de vista cronológico, a construção marxista é anterior à elaboração da teoria do valor "utilidade". A publicação dos livros de JEVONS e MENGER é de 1871 e a de WALRÁS é de 1875. Assim, a interpretação marxista já era disponível enquanto interpretação da economia 
capitalista. Esta observação tem relevância neste artigo pelo fato de já ser conhecida a ruptura entre trabalho e força de trabalho que conferiria, na análise marxista, a centralidade da categoria "trabalho".

É, então, no contexto da teoria marxista que a questão do trabalho surge na teoria econômica com maior consistência. Considera-se aqui teoria econômica marxista a construção crítica escrita por MARX em O Capital: A Crítica da Economia Política, publicada pela primeira vez em 1867.

É sabido que MARX estabelece uma profunda ruptura com os economistas políticos clássicos e esta ruptura decorre evidentemente de sua especial visão de mundo que imporá uma postura metodológica que o permitirá chegar à essência dos fenômenos. Do ponto de vista da origem do valor, MARX é um herdeiro da construção clássica e guardará traços de SMITH e RICARDO, mas, caminhando por uma trajetória absolutamente própria, onde a questão central decorre da abstração real trabalho abstrato - e da consciência da fratura histórica entre trabalho e força de trabalho.

Contrariamente aos clássicos, MARX coloca o trabalho como centro da atividade humana enquanto luta para dominar a natureza. E não só. É a partir do trabalho que os homens produzem a si mesmos e aos outros e, portanto, se relacionam entre si. E o que é trabalho? Para MARX, o trabalho é uma atividade destinada a um fim previamente definido. Assim, ele estabelece a diferença entre o trabalho humano e o trabalho dos animais, por exemplo, a abelha. Para MARX, o homem (o arquite- to, no exemplo dele) traça previamente na sua mente aquilo que será elaborado (MARX, 1978, livro 1, cap. 4).

$\bigcirc$ trabalho então é um verdadeiro exercício de liberdade, consciente, pleno. No entanto, à medida que a relação capitalista se aprofunda, e com isto se diferencia a divisão social do trabalho e se intensifica a sua divisão técnica, o trabalho se transfigura de atividade consciente em atividade alienada. $\bigcirc$ trabalho sob o capital é trabalho alienado.

Como é sabido, o processo histórico de constituição das bases materiais especificamente capitalistas consumiu séculos de transformações no processo de trabalho, bem como no processo de adequação do homem a este trabalho. Para MARX, as modificações concretas no processo de trabalho, da cooperação à grande indústria, trataram de transformar a natureza do trabalho. De atividade humana que objetiva dominar e transformar a natureza, através da inteligência, se transforma em atividade alienada. Segundo MARX, ao longo do processo de subordinação do trabalho ao capital, estabelece-se também um processo de qualificação para o capital, processo esse desqualificador da força de trabalho. Como resultante, o trabalho é parcelizado, rotinizado, submetido, dispensado, rejeitado, enfim, negado.

É necessário, então, salientar que os efeitos da divisão do trabalho se diferenciam vivamente em MARX e SMITH. Em SMITH, a grande questão resultante da divisão social do trabalho sobre os trabalhadores é a contínua extração de conteúdo, ou seja, a tarefa é parcelizada continuamen- 
te. Para MARX, porém, é a superfluidade do trabalho que revela o avanço do capital. Ou seja, o trabalho é cada vez mais dispensável ao longo dos processos de trabalho (MORAES NETO, 1991).

\section{0 trabalho e os grandes agregados econômicos}

$\mathrm{Na}$ realidade, após a contribuição marxista, quanto à elucidação da natureza do trabalho sob o capital, pouca contribuição foi acrescida, de maneira mais efetiva.

À medida que a elaboração da teoria econômica passa a explicitar de forma mais consistente o entendimento do funcionamento da economia através dos grandes agregados econômicos e, se consubstancia a Macroeconomia, a preocupação é determinar o nível e a variação do Produto, do Emprego e dos Preços. Assim, o trabalho sai de cena. No entanto, esta foi uma tendência que se estabeleceu anteriormente à teoria keynesiana e pode ser localizada no momento em que o trabalho passa a ser considerado um fator de produção.

Desse modo, o entendimento do que seja o trabalho perde o sentido e se estabelece, então, uma substituição pela questão do emprego ou ocupação. Assim, passa a ser importante o número de empregados e não o que eles fazem e por que fazem. $\mathrm{Na}$ realidade, os homens desaparecem de cena (GAUDEMAR, 1977).

Considere-se, por exemplo, a teoria keynesiana. Aqui a grande contribuição será alertar para o fato de que a economia capitalista é compatível com o desemprego involuntário.
Tal como na crise da economia política clássica, mais uma vez é a impossibilidade da teoria dar conta da realidade concreta, em plena crise dos anos trinta do século passado, quando o número de desempregados crescia assustadoramente, que se cria as condições para aceitação de novas idéias.

De acordo com a interpretação econômica vigente, seriam os trabalhadores responsáveis por seu desemprego, por não aceitarem uma redução de seus salários. Portanto, a economia (na interpretação vigente, chamada por KEYNES de clássica e centrada na lei de SAY) estava necessitando urgentemente de uma redução dos salários reais para o restabelecimento do equilíbrio com pleno emprego.

KEYNES contrapõe-se a esse argumento, destacando a incerteza de uma economia monetária capitalista na qual nada garante que a decisão individual coincida com o interesse coletivo, apontando o seu caráter intrinsecamente instável. Logo, a economia não possui leis internas que garantam o equilíbrio com pleno emprego dos fatores.

Postula então que o desemprego involuntário é inerente a este tipo de economia, pois os gastos de consumo e investimento podem ser insuficientes para absorver o contingente disponível de trabalhadores.

Para KEYNES, o componente mais instável da demanda efetiva seria o investimento, uma vez que a decisão de efetivá-lo depende das expectativas dos empresários quanto aos ganhos futuros comparados com 
o comportamento das taxas de juros. Apenas se as expectativas forem positivas, $\mathrm{O}$ investimento será realizado.

Deste modo, a única maneira de reduzir o desemprego seria através da sustentação da demanda efetiva, especificamente através da participação dos gastos governamentais. KEYNES então fornece um instrumento importante de intervenção na economia, porém, esta seria uma saída de curto prazo e com um caráter meramente anticíclico. Nestas circunstâncias, seria possível agir sobre a demanda efetiva e buscar o pleno emprego.

Quanto à natureza do trabalho, essa não era preocupação de KEYNES. Por outro lado, a reinserção do Estado "dentro" da economia, Estado esse que tinha sido alijado na construção marginalista, revigora a ação dos trabalhadores.

Para CORIAT (1982), por exemplo, KEYNES é tido como o mentor intelectual do fordismo, no sentido de ter construído uma interpretação que também evidenciava a necessidade da ampliação do consumo dos trabalhadores e, portanto, do aumento de seus salários associado à necessária presença do Estado no financiamento dos gastos sociais. Mesmo que se possa questionar este tipo de interpretação, por não considerar a ação efetiva dos trabalhadores através dos partidos políticos e de seus sindicatos na conformação da ação estatal, é inequívoca a contribuição keynesiana para fundamentar a prática concreta do Estado, sobretudo na Europa. Do Estado interventor anticíclico, a prática concreta se institui na sustentação dos gastos referentes a salários indiretos (transporte, alimentação, etc.), benefícios sociais (seguro-desemprego, assistência social, etc.) e no financiamento da produção a longo prazo, inclusive os gastos em pesquisa e desenvolvimento.

\section{Considerações finais: Em que nos auxilia a teoria econômica?}

Os últimos anos do século passado evidenciaram a insuficiência do instrumental teórico disponível para o entendimento mais adequado do que tem acontecido no mundo capitalista, notadamente, no mundo do trabalho.

O esgotamento do paradigma tecnológico anterior, baseado na energia e no petróleo, se fez, como sempre, gestando um novo, cuja sustentação tem exigido fortes modificações nas relações entre o capital e o trabalho. Dentre tais modificações, se destaca a redução do autoritarismo no processo de trabalho, a necessidade de trabalho em equipe e a incorporação do trabalhador mais qualificado no processo de tomada de decisão mais imediato, no nível da produção.

Além das modificações no processo de trabalho, sabe-se que do ângulo administrativo eliminam-se as esferas intermediárias as quais estão sendo substituídas por supervisão automatizada. Adicionalmente está em curso uma reorganização da estrutura das firmas para atender a uma demanda mais segmentada e redefinem-se os padrões concorrenciais. $\bigcirc$ conglomerado é substituído por um mix de grandes e pequenas firmas as quais passam a utilizar de forma sistemática a subcontratação (PEREZ, 1985). 
Parece evidente que está em andamento uma reordenação do trabalho dentro e fora da fábrica que se percebe inicialmente pelo caráter supérfluo que o trabalho vivo assume cada vez mais; e, em segundo lugar, pelo crescimento de formas de trabalho não-assalariado. As informações sobre a década de oitenta mostram um arrefecimento do movimento sindical no mundo desenvolvido associado a uma redução do número de seus associados (RODRIGUES, 1992). Tais evidências colocam uma dificuldade adicional no sentido de questionar quais formas de relacionamento se estabelecerão entre assalariados e não-assalariados. E ainda entre trabalho e não-trabalho. Fica mais evidente que se multiplicam as formas de trabalho relevantes, hoje, sob o capital.

Esses aspectos aqui referidos ganham maior complexidade quando a realidade mais próxima de nós é um país do $3^{\circ}$ Mundo, em especial o Brasil.

Da discussão que se iniciou neste artigo, parece ser inequívoco que a construção dos utilitaristas, ao propor o trabalho como fator produtivo, determinou o lugar que esta categoria ocupa até hoje, na grande maioria das elaborações econômicas. Desse modo, o trabalho é estudado através do funcionamento de seu mercado composto por seus demandantes e ofertantes.

É inegável a importância e centralidade que o estudo dos mercados tem para a economia. No entanto, também é inegável a sua insuficiência para o entendimento da natureza do trabalho hoje. $\bigcirc$ trabalho humano pode ser analisado sobre vários ângulos e, além de ser meio de sobrevivência ainda para a maioria da população sob o capital, pode ser visto do ângulo da realização pessoal, relacionamento social, equilíbrio psicológico, etc.

Mesmo considerando apenas o ângulo produtivo, fica, a meu ver, evidente a dificuldade de incorporação do real-concreto do mundo do trabalho. No diálogo entre as várias visões de mundo, o economista, ao reter o trabalho apenas como fator produtivo necessário para a produção de bens e serviços, comprado e vendido num mercado concorrencial (submetido a todas as hipóteses necessárias) parece ter pouco a contribuir. A maior dificuldade neste procedimento é o caráter a-histórico inerente ao fator de produção que reduz as possibilidades de um melhor domínio sobre as formas e conteúdos que têm assumido o trabalho hoje.

É interessante ainda considerar que da rápida avaliação aqui desenvolvida sobre a possibilidade da ciência econômica nos auxiliar no entendimento do que seja o trabalho hoje, parece residir, ainda, na posição marxista, as maiores possibilidades de uma reflexão conseqüente e esclarecedora.

Uma pista neste caso é fornecida pelo exemplo japonês. A insistência na utilização do trabalho em equipe, incluindo tomada de decisão no processo de trabalho e de respeito às sugestões dadas pelos trabalhadores, poderia indicar que se deu a substituição do conflito entre capital e trabalho pelo consentimento e cooperação. ${ }^{2} \bigcirc$ pró-

2 Para uma análise mais aprofundada e crítica desses aspectos, ver: FERREIRA, et al., (1991); GUIMARÃES e CASTRO (1991). 
prio exemplo japonês desautoriza esta interpretação "otimista", pois ainda é muito alto o número de horas anuais trabalhadas pelos japoneses, há a total liberdade de expansão da jornada de trabalho (sem consulta prévia ao trabalhador) bem como o tamanho expressivo da economia fora da relação capital e trabalho (TAVARES, 1988; FERREIRA, et al., 1991). Assim, SMITH já tinha razão ao afirmar que o verdadeiro conflito seria mesmo entre trabalho e capital.

Por outro lado, contudo, a utilização do fundo público como financiador da produção capitalista e de várias formas de salário indireto evidencia um significativo movimento de desfetichização das relações de produção em nível do político nos últimos cinqüenta anos (OLIVEIRA, 1988). Tal movimento revela a possibilidade real dos trabalhadores influírem nos recursos gerados pelo trabalho, porém não foi suficiente para alterar a natureza de dependência quanto à própria condição de "livres" para o capital.

Ou seja, para sobreviver, o homem ainda precisa trabalhar. Logo, a fratura histórica entre trabalho e força de trabalho permanece intocada. Assim, a mediação entre a sobrevivência cotidiana e o homem continua sendo o salário. É o acesso ao mercado de trabalho que confere o passaporte para os demais mercados.

Este fato parece ser compatível com a redução do número de trabalhadores assalariados com contratos de longo prazo no mundo desenvolvido. Mas como entender as múltiplas formas de não-trabalho?

Para RUY FAUSTO, a compreensão melhor deste ponto exige um retorno ao
MARX pré-O Capital, precisamente dos Grundrisse. Ou seja, ali MARX teria refletido sobre uma terceira forma de capitalismo que se seguiria a um momento de desenvolvimento limitado da mais-valia relativa e a um outro de desenvolvimento pleno. Nessa terceira forma, ter-se-ia a negação do trabalho como fundamento do valor e do tempo de trabalho como medida da grandeza do valor. Nessa forma:

"a riqueza não é mais produzida pelo trabalho, mas pelo não-trabalho. Isto num duplo sentido. Em primeiro lugar, a riqueza material já não depende essencialmente do trabalho. Em segundo lugar, a riqueza passa a ser essencialmente ciência (a arte, etc.) e esta é produzida no tempo de não-trabalho. Assim, a substância da riqueza não é mais o trabalho, mas é o não-trabalho." (FAUSTO, 1989, p. 63)

É bom lembrar, porém, que MARX alertou para o fato de que só se pode teorizar sobre o que existe. E, portanto, a realidade antecede à teoria (MARX, [s. d.]). Logo, na sua opinião, o concreto pensado é uma atividade post festum. No entanto, os vestígios do novo surgem ainda no velho. E aí parece residir a nossa maior dificuldade.

\section{Referências bibliográficas}

CORIAT, B. El taller y el cronometro: ensayo sobre el taylorismo, el fordismo y la producción en masa. Madrid: Siglo XXI de Espana Editores, 1982.

FAUSTO, R. A "pós-grande indústria” nos Grundrisse (e para além deles). São Paulo: Lua Nova, nov./ 1989, p. 47-67.

FERREIRA, C. Et al. Alternativas sueca, italiana e japonesa ao paradigma fordista: elementos para 
uma discussão sobre o caso brasileiro: ABET. Modelos de organização industrial, política industrial e trabalho. Anais... 1989, p. 194-228.

GAUDEMAR, J. P. Mobilidade do trabalho e acumulação do capital. Lisboa: Editorial Estampa, 1977.

GUimarÃES, J. S.; CASTRO, N. Depois de Burawoy: sobre a construção de modelos na análise do trabalho industrial. ABET. Modelos de organização industrial, política industrial e trabalho. Anais... São Paulo, abril 1991.

JACCARD, P. Psicossociologia do trabalho. Lisboa: Moraes Editores, 1969.

JEVONS, W. S. A Teoria da economia política. (Coleção Os Economistas), São Paulo: Abril Cultural, 1983.

LOWY, M. As aventuras de Karl Marx contra o Barão de Munchhausen: marxismo e positivismo na sociologia do conhecimento. 4. ed., São Paulo: Busca Vida, 1990.

MARX, K. O capital: crítica da economia política. Rio de Janeiro: Civilização Brasileira, 1978.

. "O método da economia política". In SWEEZY, P. et al. Para a crítica da economia politica. Publicações Escorpião. 3. ed., [s. d.], p. 89. 100.
MORAES NETO, B. Automação e Trabalho: Marx igual a Adam Smith? 19 Encontro Anual da ANPEC, Anais... Curitiba, 1991, p. 21-36.

OLIVEIRA, F. "O surgimento do anti-valor, capital, força de trabalho e fundo público". Novos Estudos Cebrap, no 22, out./1988, p. 8-28.

PEREZ, C. Microeletronics, long waves and world strutural change: new perspectives for developing countries. World Development, v. 13, $\mathrm{n}$ 3, 1985, p. 441-463.

RICARDO, D. Princípios de economia política e tributação. (Coleção Os Economistas), São Paulo: Abril Cultural, 1982.

. Um ensaio sobre a influência de um preço baixo do trigo nos lucros do capital. NAPOLEONI, C. Smith, Ricardo e Marx. Rio de Janeiro: Graal, 1985, 4. ed.

RODRIGUES, L. M. A crise do sindicalismo no primeiro mundo. Folha de São Paulo, mar./1992, p. 1-3.

SMITH, A. A riqueza das nações: investigação sobre sua natureza e suas causas. (Coleção Os Economistas), São Paulo: Abril Cultural, 1983.

TAVARES, M. C. "Japão realiza 'ilusão socialista”" In BUENO, R.; FARO, L. C. (org.) Capital e trabalho: os melhores depoimentos do cenário sindical. Rio de Janeiro: Rio Fundo, 1991, p. 49-54. 